\title{
Why IR scholars should care about quantum theory, part II: critics in the PITs
}

\author{
Alexander Wendt (1) \\ Department of Political Science, The Ohio State University, Columbus, OH 43210, USA \\ Correspondence author. E-mail: wendt.23@polisci.osu.edu
}

(Received 24 June 2020; revised 4 May 2021; accepted 4 May 2021)

\begin{abstract}
Part II responds to some of my critics' substantive concerns about QMASS. However, to sharpen that discussion I first introduce the idea of classical and quantum physical instantiation tests or 'PITs'. PITs are a thought experiment taking advantage of the causal closure of physics. To encourage critical self-reflection on the usually tacit ontological assumptions of our theories, PITs invite social scientists to translate their mostly qualitative, folk psychological arguments into physical descriptions, meeting classical and quantum constraints respectively, to see which feels more appropriate to the case at hand. With this diagnostic tool in hand, the paper addresses criticisms of QMASS in five areas: (1) the threat of physics reductionism; (2) the potential for epistemic repression stemming from the realist nature of QMASS' argument; (3) doubts that a quantum approach can support a genuine notion of human freedom; (4) the place of ethics and normativity in social and international life; and (5) implications for graduate methods training and quantum pedagogy more generally.
\end{abstract}

Keywords: Causal closure of physics; physical instantiation test; physics reductionism; quantum pedagogy; quantum realism

In my notes on the other contributions to this symposium, I count over 60 criticisms of $Q M A S S,{ }^{1}$ which is obviously too many to address here. Many of these, however, are off-hand objections that do not reflect close engagement with the text, much less consider obvious counter-arguments. By the same token, the remainder I have cherry picked might not satisfy my critics' expectations for engagement either. But, the combination will at least get us started.

In quantum theory context is everything, and it is no different in the dialectical context of academic exchange. Who is expected (and by whom!), to prove what, and what is allowed to be taken for granted - in short, burdens of proof - are crucial forms of epistemic structural power that have a strong bearing on how debates unfold. Ultimately, the burden of proof for a thesis as heterodox as QMASS is on me and other would-be quantum social scientists, who have to show that such an

\footnotetext{
${ }^{1}$ Wendt 2015.

(c) The Author(s), 2022. Published by Cambridge University Press. This is an Open Access article, distributed under the terms of the Creative Commons Attribution licence (https://creativecommons.org/licenses/by/4.0/), which permits unrestricted re-use, distribution, and reproduction in any medium, provided the original work is properly cited.
} 
approach helps us understand international politics (e.g.) better than we can from a classical perspective. However, in Part I of this paper I also argued that, when it comes to assigning burdens of proof to QMASS, we should not forget that classical social ontology has already failed - so far at least - important burdens of proof of its own. Both the philosophical anomaly of consciousness and the empirical anomalies of the Kahneman-Tversky results have long resisted classical resolution, and are precisely why some people are taking a serious look at quantum possibilities instead. Making classical social ontology the default would thus beg the whole question. Rather, let us judge the value of classical physical thinking against our qualitative intuitions on a case-by-case basis, and see what happens.

Still, 're-balancing' the burdens of proof in this way, with less taken for granted and thus fewer buoys to guide our discussion, does risk putting us out to sea in comparing arguments. I have a plan for that, however, which I call PITs - physical instantiation tests, classical and quantum, which I have adapted from the causal closure of physics (CCP) that opens QMASS. Let me speak first to the CCP, and then to how the PITs relate to it.

\section{Physical instantiation tests}

Recall that according to the CCP, everything in the universe, including in our minds and society, must be instantiated somewhere in the physical world. Hutchings, Kratochwil, and Prozorov reject this requirement, ${ }^{2}$ on the grounds that intentional objects like living rooms and Rivendell are not found in the world described by physics. If by that we mean found in physics textbooks then that is probably right, but I do not see how intentional objects could not be somewhere in the larger world described by those books. Intentional objects are experiences, and where are experiences if not in minds, and where are minds if not in brain/bodies, and where are they if not in the world described by physics? Is the suggestion that minds are not part of the physical universe? That sounds like ontological dualism, which I doubt my critics endorse - but if not dualism (or quantum), then what? To be clear, I agree that the experience or meaning, as such, of a living room or Rivendell cannot be reduced to physics equations. But, the CCP is not about reduction, but instantiation, just being somewhere (see below). Saying that Rivendell exists in (and perhaps between) human bodies seems like a very low physical bar for social science and should not be controversial.

Controversy arises with the fact that there are two CCPs, one constrained and governed by the laws of classical physics and the other by quantum, which have fundamentally different implications for what is physically possible in minds and society. Philosophers of science today naturally think of the CCP in quantum terms, which subsumed classical physics a century ago. However, in social science the orthodoxy still remains that quantum phenomena decohere above the molecular level, and that social ontology is therefore subject to a rump or residual classical CCP. If that assumption is wrong, as I argue in QMASS, ${ }^{3}$ then due to its materialist and mechanical ontology a classical CCP will misrepresent minds and society in the same way that classical physics misrepresents sub-atomic particles. So, QMASS was

${ }^{2}$ At Hutchings 2022, 186, Kratochwil 2022, 170, and Prozorov 2022, 161.

${ }^{3}$ Cf. Wendt 1999. 
an exploration of what the physical constraints on social life might be if we replaced our customary, classical lenses with quantum ones.

The purpose of PITs is (1) to make this normally implicit but contested physical background explicit, and then (2) to exploit it by testing qualitative intuitions about mind and society against the two CCPs. The idea of the PIT is simple. In describing any social object, event or process of interest - the behavior of a state, say, or the Iraq War - strip away all folk psychological or intentionalist language ('mentalese'), and then try to describe what is going on using just the language of physics (a rough sketch will do). Do this twice, first with the physical story constrained by classical assumptions, then by quantum ones. Social scientists are not accustomed to thinking in physical terms, since it would usually be hopelessly complex and completely unenlightening. States aside, imagine the physics of just one person's behavior, replacing 'John went to the store because he was hungry and thought food was there' with a description of his brain states, physiology and bodily movements; clearly not something one would ever do. But given the much tighter constraints on our theorizing that a classical CCP imposes, important things ride on the thought experiment: among them, the legitimacy of holistic, structural theorizing.

Consider the qualitative, folk psychological discourses of 'structural injustice' and 'structural violence,, 4 or 'systemic racism' too. On the one hand, these holistic concepts were developed precisely to describe forms of power and violence that seem to go beyond the kinetic, reductionist kind. Yet to pass a classical PIT, these concepts would have to be rendered into long concatenations of kinetic interactions between individuals. Reducing 'physical' to 'classical' in this way will in turn raise doubts about whether there is anything more going on 'physically' beyond local interactions, and thus whether social 'structures' or 'systems' exist at all. This was precisely what Margaret Thatcher concluded in her famous quote, 'there is no such thing as society', and as her policies showed, rejecting social facts by ontological fiat can have significant implications for how we understand power and politics, and ultimately deal (or not) with social problems. In contrast, as I argue elsewhere, ${ }^{5}$ the holism of such ideas will easily pass physical muster if we run them through a quantum PIT, since entanglement and non-local causation are constitutive features of quantum reality.

With those stakes in the background, let me turn now to some of my colleagues' criticisms of QMASS. I will move from more abstract to less in five areas: (1) physics reductionism; (2) epistemic repression and realism; (3) human agency and the limits of the possible; (4) the role of normativity in social and International Relations (IR) theory; and (5) methods training and quantum pedagogy.

\section{Reducing society to physics}

QMASS' sub-title is 'Unifying physical and social ontology', signaling my belief that ultimately there is only one world, not two or Popper's three, ${ }^{6}$ and that the failure to unify the supposed multiplicity of worlds is a symptom that something is wrong in our worldview. Hutchings, Kratochwil, and Prozorov reject this view, worrying that

\footnotetext{
${ }^{4}$ Much of it stemming from the work of Iris Marion Young 1990 and Johan Galtung 1969, respectively.

${ }^{5}$ See Wendt 2021.

${ }^{6}$ Much less the Many Worlds Interpretation's zillions.
} 
unification (were it even possible) would lead to physical reductionism, and with it the elimination from social science of ideas, meaning, language, and just about everything else that makes social life, well, 'social'. On this view, the promised union is really physics imperialism, just another way for positivists to impose a singular truth on the diversity of human experience and marginalize interpretivism in the process. From my perspective that would be doubly ironic, since truths in quantum theory are contextual rather than singular; and it was in part to justify interpretivist ontology scientifically that I wrote QMASS in the first place. But, investment is no insurance against folly, so let me make two points in defense of unification.

The first speaks to Prozorov's question: why is one world better than many, anyway? Does not a rainbow of ontologies protect human freedom and potential better than the boredom and 'captivity' of ontological monism? So, why try to unify worlds at all? I would give two reasons to start. The obvious one is deeper understanding. Common sense and the history of science alike suggest that a theory that can unify into a larger whole what otherwise seem like unrelated parts is superior to one that cannot. Moreover, we are dealing here not just with a local unification, but a global one, since quantum theory offers a universal language for the physical and social sciences. To reject this language a priori would seem to reject trying to understand what ties things together at all. Sometimes ignorance is bliss, but as a principle of science?

Second, even if we grant the desirability in principle of unifying physical and social ontologies, we might still worry about the terms of the deal, given the asymmetry of the PIT (there is no matching social instantiation test, or 'SIT'). ${ }^{7}$ By privileging the physical, are we not supporting reductionist efforts to eliminate fuzzy, folk psychological talk in social science, as advocated by Skinnerian behaviorists and eliminative materialists? That would indeed be imperialism, although the joke was on behaviorists and eliminativists, who in social science became 'the eliminated', not the folk psychologists. However, why would not a quantum PIT pull us the same way, toward 'quantum eliminativism' about consciousness?

The reason is the conceptual distinction I draw - to me the most important in the book, yet frustratingly neglected by these reviewers - between 'material' and 'physical'. ${ }^{8}$ In the past, it was natural to conflate the two terms, since classical physics (the original authority on the physical) was invented to describe the behavior of purely material objects like rocks and planets, which were hard on the outside and had no subjective inside. However, it is precisely that hard, classical sense of physicality which breaks down in the quantum world, and importantly, in a way that offers a clear opening for consciousness: in the collapse of the wave function, which has no classical cause. ${ }^{9}$ So, although the CCP does privilege the physical world, it is not your grandma's illusionist, classical physical world anymore, which my critics still seem stuck in, but a quantum one that views consciousness

\footnotetext{
${ }^{7}$ Although see QMASS' suggestion for a 'pan-social' metaphysics on p. 280.

${ }^{8}$ Although she does not put the distinction in this way, something like it seems to be at work in Karen Barad's 2007 conception of quantum materiality.

${ }^{9}$ Among recent arguments to this effect, see especially Georgiev 2018.
} 
as part of the physical order, not only for us, but for every other organism too. ${ }^{10}$ Moreover, as I argue in Chapter 6, this 'neutral monist' ontology is consistent with an epistemological duality, because it implies distinct insider and outsider perspectives on mental and social life. ${ }^{11}$ Far from being eliminated by physics, therefore, the reality and importance of intentional objects and subjectivity is secured by this ontology. Rivendell is physical, in short, imprinted in brains and books, yet only because it is quantum physical can it be experienced as 'Rivendell'.

In sum, QMASS summarizes an emerging re-conceptualization of the physical basis for attributing conscious, intentional states to our fellow human beings, both in ordinary life and in social science. Such states of course have long been the focus of interpretivist scholarship, and so there is not just the intellectual progress of finding a place for consciousness in Nature. There is hopefully now also potential 'political' progress of integrating interpretivist work into social science on a more equal basis. Yet, it is not only interpretivists who benefit from having a physical basis for consciousness, but also any positivist who invokes intentional states in their work, like most rational choice theorists. ${ }^{12}$ From an eliminative materialist standpoint, rational choice is just as epistemically suspect as interpretivist theories, if it invokes, even implicitly, the illusion of consciousness. Letting everyone get on with their work might not seem like much. But, it could end some needless arguments, and maybe even get us more respect from physical (sic) scientists as well.

\section{Epistemic repression and realism}

Relative to the mechanical determinism of the $19^{\text {th }}$ century worldview, the quantum revolution in physics dramatically expanded our sense of the openness and potentialities of the physical world, and in QMASS I argue there is the same potential in the social world. Thus, I was surprised to see so much anxiety among my critics that if imported into social science quantum theory would have the opposite effect, of being epistemically repressive and closing off innovations in the field. Two worries stand out: Hutchings' that QMASS embodies a dangerous Will to Truth; and Chernoff, Hutchings, and Kratochwil's criticisms of QMASS' realism.

\section{Is searching for truth dangerous?}

Hutchings thinks that QMASS privileges scientific over other forms of knowing, and as such harkens back nostalgically to an imagined past in which an elite caste of social scientists might hope to predict, and therefore control, society - naturally, for the good of all... Three points.

First, my purpose of course is not to privilege scientific over non-scientific ways of knowing in general - personally, I would much rather experience a sunset than read the physics of one. My aim is to help redefine what 'scientific' knowing in

\footnotetext{
${ }^{10}$ In this context, I do not understand Hutchings' (2022: 189) criticism that QMASS reinforces human exceptionalism, since its panpsychism and vitalism apply to all organisms, not just people.

${ }^{11}$ Cf. Hollis and Smith 1990.

${ }^{12}$ Although some rationalists resist such a 'mentalistic' interpretation of the theory; for this debate - and a strong vote for mentalism - see Dietrich and List 2016.
} 
social inquiry looks like, such that it recognizes the complementarity - in the quantum sense $\mathrm{s}^{13}$ - of objective and subjective, or outside and inside, points of view. As I suggest in QMASS' Conclusion, this points toward a participatory epistemology attuned to pervasive subjectivity in Nature - an epistemology for Goethe's living, breathing world, not Newton's dead, mechanical one. ${ }^{14}$ As such, if quantum is also a human science, then it will necessarily embody a Will to Understand, not just to Explain or Know, the irreducibility of which is increasingly recognized not just in the philosophy of social science, where it is commonplace, but of physical science too. ${ }^{15}$ In that light Hutchings' criticism seems to betray an implicit classical conception of 'science' that I see no reason to privilege.

Second, as an example of the dangers of the Will to Truth Hutchings asks what is the 'point' of quantum decision theory's empirical success? It is a good question. Assuming that Quantum Decision Theory (QDT) has now mostly accounted for the Kahneman-Tversky anomalies, what more is there for it to do? Her worry seems to be that because it predicts better than its classical cousin, it might inspire a new generation of authoritarian social engineers. I read the lesson of QDT differently, in two respects.

One is that it is really a kind of 'Social Control Impossibility Theorem'. QDT's predictions are not just more accurate; they strongly suggest that it is impossible to fully control human behavior, period. Not just because of poor data, complexity, or other familiar classical epistemological limits, but because of two features of quantum social ontology: the non-deterministic nature of subjectivity itself (free will), and the highly contextual behavior of all quantum systems. Of course, policymakers could still enlist quantum decision theorists to 'nudge' human behavior in certain directions rather than others, and thus possibly use the idea for ill. But, that is true of all social theories, even critical ones, and as such seems a far cry from the Orwellian fantasies that these days probably live less in positivists' dreams than interpretivists' nightmares.

The other implication of QDT's success goes beyond its technical application (the interesting scope for which may indeed be limited), to what I see as its real, revolutionary lesson. If cognition and decision-making really are quantum, then it would behoove us to consider the assumptions about human agency that we are currently making in our work, subject them to classical and quantum PITs, and then see if we want to change anything. Because what is at stake is big: the way social scientists (and ultimately everyone; see below) at least implicitly model the mind and society, whether or not we learn the math. So, let me ask of Hutchings, would it not matter at all to her worldview and approach to politics if it were shown that people are quantum rather than classical beings? And if it did matter, what difference would it make?

This brings me to my last point about the Will to Truth. What is the alternative: a Will to Ignorance? A refusal to know, a turning away from facts, even when the opportunity to know presents itself? I cannot see Hutchings saying that, but if not

\footnotetext{
${ }^{13}$ Roughly speaking: incompatible, individually incomplete perspectives that are jointly necessary for a complete description.

${ }^{14}$ Although don't ask me about Goethe, see Hinchman and Hinchman 2007 instead.

${ }^{15}$ See Khalifa 2019 for an entry into this thriving debate.
} 
then why not? If humans were not driven to know the truth we would never have invented science and philosophy. Yes, knowledge is power, but in the quantum world there is no singular, universal truth, only many potential perspectival ones. Moreover, among the actors in modern society social scientists' real power is minuscule, and as such I would lament an academy in which we are afraid to exercise what little we have by trying to know society as best as we can. I would highlight instead the positive side of trying to know. It is only because Busemeyer and others had a Will to Truth that they asked whether a quantum approach might account for the Kahneman-Tversky anomalies. And it is only because they applied rigorous science to that question, that we now have essentially a proof of the limits of mainstream positivism. I can see how Kydd might find that dangerous, but why Hutchings? Social science's problem in the past has been a classical ontology, which Hutchings and I would both criticize - but which she seems strangely reluctant to let go of as the arbiter of 'science'. So, which is worse, sometimes social science being used for ill (Will to Know), or being blindsided by preventable harms (Will to Ignorance)? I'm with the Knowers.

\section{Realism and quantum social science}

Chernoff, Hutchings, and Kratochwil all highlight a perceived threat to social science posed by the realist nature of QMASS' interpretation of quantum social science, the assertion that minds and society really are quantum. In different forms the worry seems to be that this ontology might be weaponized, used to overrule local substantive knowledge and standards in IR or elsewhere in favor of a priori ontological ones, ${ }^{16}$ and/or throttle the development of ideas that are not in step with the new quantum dispensation. Should we reject (e.g.) rationalist IR theory simply because it has a $19^{\text {th }}$ century axiomatic structure? With a realist view of quantum social science there is the potential for epistemic coercion, just like realism has in classical social science.

By the same token, quantum social science seems less threatening when interpreted through the lens of realism's traditional rivals, instrumentalism, and pragmatism, because they make no ontological commitments to social wave functions and other unobservables, much less to what people 'really are'. With no apparent ${ }^{17}$ ontology to defend, there is no incentive to rule out theories that are classical in character, and so quantum theory becomes just another tool that IR scholars might pick up to solve problems at hand. This pragmatic attitude is probably why instrumentalism is the most common stance today among quantum decision theorists themselves, with their 'as if language of quantum-'like' effects, which allows them to do their empirical work without getting bogged down in metaphysical debates. It is hard here to tell whether the real object of my critics' ire is my realist interpretation of quantum social science or quantum social science per se. But perhaps with the realist thorn removed they would have gone easier on quantum.

\footnotetext{
${ }^{16}$ Cf. Monteiro and Ruby 2009.

${ }^{17}$ I say that because I am not convinced that my critics are free of an implicitly classical social ontology. The easiest PIT here would be whether they believe in the possibility of social action at a distance, and if so how.
} 
That naturally invites the question of why I took a realist approach, but I explained that in the book and it is not crucial here. For although QMASS was written the way it was to advance a realist view of quantum social science, as I also make clear up front, I would be perfectly happy if people read the book from an instrumentalist perspective instead, as nothing more than a source of inspiration and potentially useful tools. There is no 'true believer' requirement to do quantum social science, in other words, just a willingness to entertain some pretty strange ideas. Indeed, instrumentalism and pragmatism should encourage such playful experimentation, precisely because they make no ontological commitments. ${ }^{18}$ And conversely, the scientific realism of my 1999 book is itself a doctrine that quantum theory calls into question! ${ }^{19}$ Realism implies an independently existing, objective reality that can anchor knowledge claims, whereas in the quantum world, all we have are probabilistic wave functions, the actualization of which depends on how they are measured.

Given the pragmatist interpretive option, the apparent desire of some critics to 'kill' quantum social science is puzzling to me, but either way they miss the mark completely when they associate quantum realism with a correspondence theory of truth. It would make no sense for any quantum theorist to defend such an idea, since there is no one, objective truth to be defended, only multiple perspectival ones. Instead, what we see among quantum theorists of a realist disposition are efforts to redefine 'realism' to incorporate the unique aspects of quantum reality, like the entanglement of wave functions and the creative, open-ended quality of measurement. Hence 'open' realism, 'participatory' realism, and so on. ${ }^{20}$ I have not absorbed these ideas yet, but they are a far cry from the classical scientific (and also 'critical') realism my critics have in mind. How about we all go study the debate about realism in quantum theory, and then talk again? My guess is that it would make a novel and fruitful contribution to IR's epistemological debate.

In the meantime, in my view quantum realism poses no threat of ontological foreclosure on extant IR scholarship, including rationalist theories that are explicitly classical in structure. That is because mathematically and physically speaking quantum theory recovers classical theory at the limit. So just as quantum physics did not invalidate classical physics for all purposes, so quantum social science would not wholly invalidate classical either. For example, one can imagine that the more predictable social environments are, the more useful classical approximations will be. What would change is that where we once assumed without thinking that 'rational choice' was necessarily about classical logic and probability, this is now a question. Is $\mathrm{X}$ a case where it makes sense to use the 'collapsed form' of the wave function? Why or why not? What would change, in short, is the privileged status of rational choice as the default, not our ability to use the theory to explain world politics. That looks to me like an opening in the field, not closure.

Indeed, when it comes to weaponizing the $\mathrm{CCP}$, the real threat is from the ancien regime, because classical theory is so much more mechanical and constrained than quantum. Claims of entanglement and 'action at a distance' in social life would

\footnotetext{
${ }^{18}$ Cf. Chernoff 2022, 154.

${ }^{19}$ See QMASS, Ch. 4. Its affront to realism is one reason that Einstein disliked quantum theory so much.

${ }^{20}$ See respectively d'Espagnat 2006, 237-41 and Rickles 2019.
} 
never survive a classical PIT, and so any social theory that depended on them - like those about structural injustice and violence - would be problematic from the start. My point of course is not to affirm all claims of structural violence. It is that unlike in the classical regime of truth, where they may be excluded a priori as unscientific, in a quantum regime they are admissible and as such can be evaluated by precisely the kind of local disciplinary standards that my critics and I agree should have priority.

\section{Agency, events, and the possible}

Prozorov's essay provides an opportunity to further expand on how a quantum perspective would open up rather than limit social and IR theorizing.

In its ideal form, if the error term could be completely eliminated, classical social science would show why events had to happen exactly as they did, even if beforehand no one could have predicted them. ${ }^{21}$ Like the classical model of material objects from which it derives, modern social science has a deterministic worldview ontologically, even if not epistemologically (because in practice the error term cannot be eliminated). As such, it seems purpose-built to squeeze human agency out of the picture (there is your error term!). By the same token, modern social science privileges actuality over potentiality, since in a deterministic world nothing else or more could happen than does happen, so there is no genuine notion of possibility at all. In classical ontology there is only Being, which I take to mean simply what is or must be. It is a cold and heartless view, but perhaps Kydd is right that I should get used to it.

Prozorov and I share a resistance to the tyranny of Being, but following Badiou he is skeptical that a quantum approach can support a conception of agency and social life as genuinely contingent. I do not know Badiou's work, and I would be especially interested to learn how it differs from or goes beyond quantum logic. But in the meantime - if I may play the burdens of proof game - I think the bar for Prozorov here should be high. That is because quantum theory already contains what appears to be the perfect solution to the classical problem of contingency: the wave function. When not measured it exists only as a structure of weighted potentials, a superposition of alternative possible realities, and to that extent it is less-than-Being - but as a structure of potentiality, the wave function is also more than Nothing. And then when measured, it collapses into an event, or Being, but non-deterministically, not just in an epistemic sense, but an ontological one as well. The fact that wave function collapse is non-deterministic is one of the central challenges quantum physics poses to the classical worldview. However, even within the community of quantum theorists, there has been much ensuing debate on what that means for the relationship between potentiality and actuality (Heisenberg), the implicate order and the explicate order (Bohm), and so on. ${ }^{22}$ Nevertheless, throughout this debate, all sides have agreed that they were talking about a physical process (broadly defined) that respects the laws of quantum physics.

\footnotetext{
${ }^{21}$ See Kurzman 2004 for an interesting discussion of the epistemic tensions this can create.

${ }^{22}$ See Camilleri 2009, especially 165-71, and Williams 2019 and Pylkkanen, 2007 respectively.
} 
From here, my question to Prozorov would be: what more do we need in order to install genuine freedom into our worldview? His answer (with Arendt) is a 'rupture of contingency', where something like a revolution is not truly an event unless it is reducible to neither causes nor ends, and 'violates ontological laws'. ${ }^{23}$ On this view, the collapse of the wave function is not a genuine event, because it violates no physical laws and originates in a preexisting structure of potentiality and thus could have happened. We must instead look for what is outside structure and thus could not have happened beforehand.

If events must spring from literally Nothing, from a world without any structure at all (even one as ghostly as a wave function), then they will fail both PITs and violate the CCP. Events would have to be literally 'miracles' in the natural order. To me that is counter-intuitive, and suggests that Arendt has an implicitly classical conception of structure and contingency. However, to really reply I would need to hear more about (a) what problem with quantum thinking Prozorov is trying to fix with such a drastic step, and (b) what physical constraints, if any, he would accept in place of a quantum CCP. In the meantime, in our search for agency I would urge most of us to resist the temptation to look immediately 'beyond quantum'. ${ }^{24}$ Or at least not until we have digested the lessons of the greatest minds in physics, as they dealt with issues that social scientists would find surprisingly familiar. Sequestered from the quantum revolution for over 90 years, we are just beginning our own encounter with its profound challenge to the modern episteme. Figuring out if and how it should change our thinking about society deserves whatever time it takes.

\section{Social theory and normativity}

A different set of critiques focuses on how a quantum approach would handle the normativity of social life, in two senses. One is normativity in the political theory sense, with Chernoff wondering what role ethical concepts could play in my world. The other is explanatory or sociological, with Kydd skeptical of the lessons that quantum game theory teaches.

\section{On the possibility of ethics in a physical world}

Recalling burdens of proof for a moment, here I think we really have to acknowledge that the first shoe is on the other foot: that before we even get to quantum social theory, its classical counterpart already has a big problem with ethics. The reason is simple: ethics requires consciousness, and no classical theory of consciousness is on the horizon. Robots and zombies, which lack consciousness, cannot be good or evil, so it makes no more sense to condemn them than condemning the weather. Of course moral philosophy and political theory are about people, not robots and zombies, and scholars and spiritual figures have spent centuries developing a rich folk psychological discourse for human ethical experience. But, if ethics too must be physically instantiated, what does that look like in a classical PIT, where physical means material and consciousness is an illusion? If our ontology has no place for consciousness, what then of ethics? Is it too an illusion?

\footnotetext{
${ }^{23}$ Prozorov 2022, 163.
}

${ }^{24}$ Though also see Burgess 2018. 
QMASS' explanation might be wrong, but at least it tries to 'save the appearances' of consciousness, rather than ignore, reduce or explain it away. Does that mean I have a theory of ethics? Of course not. ${ }^{25}$ But, such a theory is at least conceivable in a world of quantum subjectivity, in a way that, given the mind-body problem, it seems not to be in a classical one.

Chernoff responds that if in a quantum world both ethical and non-ethical thought is made of the same physical stuff (collapsing wave functions), then it is difficult to understand the moral difference between torture and a garden wall. ${ }^{26}$ I do not see why this follows (and would note that it would be equally true in a classical world, where everything is material). Yes, all thought comes from wave functions, but its actualized, collapsed content will depend on who the subject is, what they are attending to and why, what the local context is, the remote, historical context, and so on - and as such may vary hugely. Torture has special status because we experience it as involving the pain of others, which we do not experience with garden walls. That is probably partly because garden walls are not alive, although people obviously had different views about torturing living things in the past... But either way, how is quantum consciousness theory, which is all about recognizing the ontological status of experience (both human and of all organisms), a threat to making them objects of ethical concern? If anything it would seem a precondition.

\section{Entanglement and the default setting for social theory}

Kydd's complaints about quantum normativity are empirical rather than normative. The most important I take to be that QMASS and entanglement specifically provides no basis for reversing our traditional privileging, going back to Hobbes, of conflict over cooperation as the default setting for social, political, and especially IR theory. Kydd is right to point to the fundamental difference here between the two perspectives, which is rooted in the holism of entanglement. ${ }^{27}$ To set this up let me briefly highlight the individualism of the standard model.

As is well known, the doctrine of methodological individualism (MI) enjoins social scientists to work in a bottom-up fashion, breaking apparent wholes like states and the international system down into their constituent parts (individuals), and then trying to put them back together from a theory of the parts' interaction. Although writing long before 'MI' existed, Hobbes and Locke clearly attempted to ground their social and political theories in a state of nature, where individuals lived before there were societies at all. Although Hobbes and Locke disagreed about how civilized (or 'social') people were in this condition, they agreed that the first and most fundamental problem of life in the state of nature is maintaining order - of getting individuals to join a social contract to enforce and obey the rules of society in the face of incentives to defect. Especially for Hobbes, failure to do so implies an ever-present danger of civil conflict, so the latter becomes the default setting for both explanatory and normative theorizing, not least in IR.

\footnotetext{
${ }^{25}$ See Fierke 2017 and Zanotti 2018 for good starts on that journey coming out of IR.

${ }^{26}$ Chernoff 2022, 156 .

${ }^{27}$ Holism was also a central principle of Wendt 1999, especially Ch. 4, and as such provides one continuity with QMASS.
} 
All this is familiar; what I want to highlight is the role of classical physical assumptions in making MI the ontological foundation for state of nature theorizing, and from there for liberalism more generally. MI assumes that individuals are 'fully separable', which means not entangled in a quantum sense. That might seem obvious, since our bodies are separated by skins, and ultimately we die separately too; and, at least in a classical PIT, our minds must be inside our brains, which are also inside our skins. Common sense perhaps, but it is precisely this model of the fully separable individual that quantum social theory calls into question.

Although I have not given much thought to the rest of our bodies, in the concluding chapters of QMASS I argued that our minds are entangled quantum mechanically - such that we are not fully separable, but in Paavo Pylkkanen's words, 'correlated projections of a common ground'. ${ }^{28}$ As for Kydd's question, the correlations come from socialization, and begin to form from the moment we are conceived, when our senses are entangled immediately with everything around us. But, it is only after children learn language that correlations deep enough to sustain society can really emerge, and so I see shared language as the core of human entanglement. Interestingly, although I cannot go into details here, quantum semantics shows that language exhibits a number of quantum properties, including systematic violation of Bell inequalities, which in physics is a key marker of entanglement. ${ }^{29}$ And as also in physics, where the context of the whole measurement determines the probabilities for observing certain parts, in quantum social theory the structures of society work in a top-down fashion to shape the dispositions and behavior of individuals. Viewed in this holistic light, the problem of social order is the opposite of how individualists see it. For them it is about inducing separated individuals to get along well enough to overcome the Hobbesian problem. For me - and following Karen Barad - it is about learning to create or enact separable individuals from a social whole with which we have and always will be entangled. ${ }^{30}$

If human beings are entangled through language, then that could be very significant for our default expectations about the state of nature (sic), because entanglement plays a key role in quantum game theory. In quantized versions of standard mixed-motive games - Prisoner's Dilemma, Chicken, and so on. - the greater the entanglement, the more cooperation we expect, above and beyond classical predictions. And as in psychology, this is exactly what experimental game theorists have found, that people cooperate more than they 'should' according to classical rationality in strategic interaction. So, if we are going to engage in state of nature theorizing at all (at least where language is present), then let us recognize that this 'nature' and its denizens are inherently social - more like a giant family than the atomistic individuals of classical liberalism.

\footnotetext{
${ }^{28}$ See Pylkkanen 2007, 145.

${ }^{29}$ See specifically Beltran and Geriente 2019 , as well as more generally extensive work in this area by Diederik Aerts and Peter Bruza.

${ }^{30} \mathrm{Barad} 2007$. It is important to note that social and political theorists of various persuasions (feminist, post-structural, relational, even Wendt 1999) have articulated versions of this holistic view of the individual for many years without any benefit of quantum social theory. That raises a 'value added' question for the latter, to which my short answer is that quantum makes these arguments more scientific and thus likely to have more traction. But, this is for a much longer conversation. For a start see Wendt 2021, and cf. Albert and Bathon 2020.
} 
Kydd is surprisingly skeptical of quantum game theory, calling its central insights 'trivial'. ${ }^{31} \mathrm{He}$ argues that in the classical tradition we already have cooperative game theory, which assumes that agreements are enforceable. As a result, it begs the hard questions that non-cooperative game theory deals with, which of course have special relevance to the anarchic world of IR. Yet, my understanding is that Kydd is mistaken here, that quantum game theory is a form of noncooperative game theory, not cooperative. That is precisely what makes it nontrivial, that in just 20 years it has spawned hundreds of articles.

Finally, to Kydd's point that QMASS lacks a theory of conflict: if he means a theory that specifies the conditions under which conflicts of X type will emerge, then he is of course right - although then I do not have a theory of cooperation either, all of which would have taken another book. However, if Kydd means that quantum IR theory would preclude war or other conflicts, then that makes no more sense than saying the current 'pro-conflict' default of classical IR theory precludes cooperation. Even more so than the classical, the quantum world is one of probabilities, not necessities, so even if entanglement is high, conflict is always still possible. Could the conditions precipitating such breakdowns, even if probabilistic, be studied by IR scholars? Sure, why not? Being 'correlated projections of a common ground' does not mean that peace, love, and dope conquer all. It just gives an extra boost to cooperation, and in so doing brings game theory more into line with how people really behave.

\section{Methods training and quantum pedagogy ${ }^{32}$}

Hutchings and Kratochwil growl that the implication of QMASS boils down to 'more math' for social scientists, which cannot capture meaning and subjectivity, and as such in their view not only does nothing for interpretivist social science, but further marginalizes it. Since I cannot do the math myself, that would be yet another irony of all my work...; however, I think the criticism misunderstands the larger project.

The math is obviously necessary to do quantum decision and game theory, where there is work still to be done, especially at the intersection of theory and experiment and there is no harm in that, right? Nonetheless, at this point it is unclear how many more interesting technical applications there are. However, that to me misses the real value of learning the math. Quantum theory is not just 'more' math, but a completely different kind of math, one that would support qualitative quantum social science, by educating us to think about the world in quantum terms even when using folk psychological discourse. This speaks to an issue that is at the heart of what I see as the transformative potential of quantum social science.

The issue is pedagogy, in the first instance the classical methods training we currently give to almost all graduate students in the human sciences. What this does is not just teach them to use specialized statistical tools, important although that is. It also hard wires their brains - our brains - to 'see' a mostly invisible social world as if it were full of classical objects and 'mechanisms'. The bias in our training is clearest on the positivist side, where quantitative methods courses almost never go beyond classical probability theory and logic, and which even qualitative scholars who prefer their positivism 'lite' do not question. Classical assumptions are harder

${ }^{31}$ Kydd 2022, 138.

${ }^{32}$ The ideas in this section are expanded further in Wendt 2021. 
to see in interpretive methods, since (e.g.) discourse analysis, genealogy, or textual interpretation are all about trying to recover meanings - which in QMASS' ontology are quantum phenomena. However, we do see a clear classical footprint in interpretivists' rhetorical strategy: implicitly conceding the CCP, and thus social science or Explanation to positivists, and trying to seize the epistemological (moral?) high ground by doing something else, Understanding, instead. As Prozorov puts it to his fellow critical theorists, 'While [interpretivists] venture to overcome the limits of positivism, they do so through bracketing off the ontological question altogether, implicitly presupposing the "classical" ontology of the positivists but denying its relevance for their enterprise'. ${ }^{33}$ Quantum theory highlights this implicit assumption by showing that science is actually consistent with two, radically different views of Explanation, and thus we are not forced simply by 'logic' to go with classical categories. On the contrary, we now have a choice: if social scientists are going to use logic and probability in our work (and it is hard to see even interpretivists avoiding those altogether), then which kind should we use, classical or quantum (or both), and under what conditions? If the brain is a classical computer, then the answer is simple, just keep doing what we are doing, and interpretivists can go to the humanities. But, what if the brain is a quantum computer, so that Cognition, Experience, and Will - the three faculties in QMASS' toy model of subjectivity - are quantum too? This would have at least two important implications for current methods pedagogy.

First, classical training will generate persistent anomalies, because it teaches us to use classical categories to study what are actually quantum phenomena. Consider that the Kahneman-Tversky 'anomalies' are not really anomalous to intuition, only to theory. It is not that test subjects' judgments that Linda is more likely a feminist bank teller than just a bank teller do not 'make sense'. ${ }^{34}$ They make perfect sense - you and I and apparently Kydd too ${ }^{35}$ would probably all say the same, even knowing it is not 'logical'. But, that is precisely the problem. It is classical theory that sees an anomaly here, which disappears when we use quantum theory instead.

The second implication of classical methods training is deeper, since it is not just about social scientists, but anyone educated under the modern regime of truth. That is because the mental hard-wiring that such training produces does not begin in graduate school or even college - it begins in pre-school. It is there, in Level 1 of the classical PIT, that we imbibe the fundamental principle of classical social ontology, which is that the intangible intentional objects in our minds including images of other people - follow the same rules as the tangible, material objects described by classical physics. If this assumption is mistaken, then internalizing it in effect means learning to repress awareness of our naturally entangled, free and supple (not to mention conscious!) quantum selves - that is, our humanity - in favor of a 'rugged' individualism of separable, deterministic machines. The loss in entanglement here seems particularly grievous given its key role in facilitating cooperation in quantum games.

Now consider that in the West, at least implicitly we have had two to three centuries of such classical pedagogy about the mind and society - and the rest of the

\footnotetext{
${ }^{33}$ Prozorov 2022, 159.

${ }^{35}$ Kydd, 2022, 137.
}

${ }^{34}$ For a brief overview of this famous example see QMASS, 159-60. 
world is now 'catching up' fast. It is not hard to imagine such a system producing precisely the kind of individualistic and self-interested subjects that one would find in a Hobbesian state of nature (or capitalism for that matter) - thereby seeming to vindicate the individualism and conflict-as-default mentality that dominates social science today. From a quantum perspective, however, what we are actually dealing with here is a self-fulfilling prophecy that produces false consciousness - of humans as objects alienated from Nature, each other, and above all ourselves. Such a view seems far less capable of confronting the challenges of the $21^{\text {st }}$ century than its quantum counterpart. It is an almost tragic situation that physicist Robert Oppenheimer envisioned in 1956, which I quoted at the beginning of QMASS: '[T] he worst of all possible misunderstandings would occur if psychology should be influenced to model itself after a physics which is not there anymore'. From this perspective, an explicitly quantum pedagogy would be inherently critical and transformative. ${ }^{36}$

Does this mean that the social sciences, and indeed educational institutions down to pre-school, should now begin to 're-wire humanity' by teaching a quantum curriculum over a classical? (Now there is an Orwellian image for Hutchings although imagine continuing the classical alternative instead!) Well, even if that were desirable in principle, in practice it would be impossible because even the most technically sophisticated social scientists have almost never been exposed to quantum theory, and when they are, in my experience most find its mathematics completely bewildering at first. So, who would teach the courses needed to teach the teachers? Moreover, even on a purely intellectual level, it is clearly too early to argue for wholesale changes in graduate methods training, much less education in general, when quantum social theory has only just begun to prove its worth.

However, what definitely has changed is that today it is no longer possible to argue that methods training must by definition be classical. There are now two methods games in town, the new even more scientific than the old. So, although classical methodologists should obviously not be expected to just pack up their bags and go home, we should now be able to expect a justification for their One Methods policy. Why not also teach quantum methods, so that more can explore their potential by comparing them to classical methods? Absent an argument against - an argument, not ritual incantations of a dying worldview -I see no reason to consider classical social science an unquestionable baseline of Established Knowledge. Yes, it is Established (which counts for something), but partly as Dogma as much as Knowledge, and true only in the limit.

\section{Second conclusion}

IR scholars seem especially given to proclaiming 'turns' in our field ${ }^{37}$ - the practice turn, the emotions turn, the relational turn, and so on. Quantum social science is not a turn. It is a question. And it is not going away, because quantum physics is not going away, and nor are the 'uncomfortable facts' for classical social science that it might address (see Part I). Whether or not social scientists choose to confront the question, in all of our research we now face a implicit choice of which set of

\footnotetext{
${ }^{36}$ Cf. Freire 2000.
}

${ }^{37}$ Baele and Bettiza 2021. 
categories to use. Running our intuitions through PITs is one practical way to help answer that question and sharpen our thinking in the process.

So yes, as is often said of quantum theory itself, the idea of a quantum social science is 'weird'. But, weird compared to what - thinking that mental objects behave according to the same mechanical principles as material ones? The only way to find out will be through a long conversation between quantum and classical perspectives, both positivist and interpretivist, on the physical nature of the mind and society. This symposium has been a good start. Thank you to everyone again.

Acknowledgements. I am grateful to Duncan Snidal for detailed comments on the first draft of this paper too many years ago, to Stefano Guzzini for several long exchanges in the interim trying to help me understand, and to a rotating brain trust of graduate students for ongoing support and critical discussion.

\section{References}

Albert, Mathias, and Felix Maximillian Bathon. 2020. "Quantum and Systems Theory in World Society: Not Brothers and Sisters but Relatives Still?." Security Dialogue 51 (5): 434-49.

Baele, Stephane J., and Gregorio Bettiza. 2021. "Turning' Everywhere in IR: On the Sociological Underpinnings of the Field's Proliferating Turns." International Theory 13 (2): 314-40.

Barad, Karen. 2007. Meeting the Universe Halfway. Durham, N.C.: Duke University Press.

Beltran, Lester, and Suzette Geriente. 2019. "Quantum Entanglement in Corpuses of Documents." Foundations of Science 24: 227-46.

Burgess, J. Peter. 2018. "Science Blurring its Edges into Spirit: The Quantum Path to Atma." Millennium 47 (1): 128-41.

Camilleri, Kristian. 2009. Heisenberg and the Interpretation of Quantum Mechanics. Cambridge: Cambridge University Press.

Chernoff, Fred. 2022. “Truth,' 'Justice' and the American Wave... Function: Comments on Alexander Wendt's Quantum Mind and Social Science." International Theory 14 (1): 146-58.

D’Espagnat, Bernard. 2006. On Physics and Philosophy. Princeton, N.J.: Princeton University Press.

Dietrich, Franz, and Christian List. 2016. "Mentalism versus Behaviourism in Economics: A Philosophy of Science Perspective." Economics and Philosophy 32: 249-81.

Fierke, Karin. 2017. "Consciousness at the Interface: Wendt, Eastern Wisdom and the Ethics of Intra-Action.” Critical Review 29 (2): 141-69.

Freire, Paulo. 2000. Pedagogy of the Oppressed. New York: Bloomsbury Academic.

Galtung, Johan. 1969. "Violence, Peace, and Peace Research.” Journal of Peace Research 6 (3): 167-91.

Georgiev, Danko. 2018. Quantum Information and Consciousness - A Gentle Introduction. Boca Raton, Fla.: CRC Press.

Hinchman, Lewis, and Sandra Hinchman. 2007. "What We Owe the Romantics." Environmental Values 16 (3): 333-54.

Hollis, Martin, and Steve Smith. 1990. Explaining and Understanding International Relations. Oxford: Clarendon Press.

Hutchings, Kimberly. 2022. "Empire and Insurgency: The Politics of Truth in Alexander Wendt's Quantum Mind and Social Science: Unifying Physical and Social Ontology." International Theory 14 (1): 183-92.

Khalifa, Kareem. 2019. "Is Verstehen Scientific Understanding?” Philosophy of the Social Sciences 49: 282-306.

Kratochwil, Friedrich. 2022. "The Strange Fate of the Morphed 'Rump Materialism': A Comment on the Vagaries of Social Science as Seen Through Alexander Wendt's Quantum Mind and Social Science.” International Theory 14 (1): 169-82.

Kurzman, Charles. 2004. "Can Understanding Undermine Explanation? The Confused Experience of Revolution." Philosophy of the Social Sciences 34: 328-51.

Kydd, Andrew. 2022. "Our Place in the Universe: Alexander Wendt and Quantum Mechanics." International Theory 14 (1): 130-45.

Monteiro, Nuno, and Keven Ruby. 2009. "IR and the False Promise of Philosophical Foundations." International Theory 1 (1): 15-48. 
Prozorov, Sergei. 2022. “Otherwise than Quantum.” International Theory 14 (1): 159-68.

Pylkkanen, Paavo. 2007. Mind, Matter and the Implicate Order. Berlin: Springer.

Rickles, Dean. 2019. “Johntology: Participatory Realism and its Problems." Mind and Matter 17 (2): 205-21. Wendt, Alexander. 1999. Social Theory of International Politics. Cambridge: Cambridge University Press.

Wendt, Alexander. 2015. Quantum Mind and Social Science. Cambridge: Cambridge University Press.

Wendt, Alexander. 2021. "Quantum Theory as Critical Theory: Alienation, Entanglement, and the Politics of Social Physics." Unpublished manuscript, The Ohio State University.

Williams, George. 2019. "Quantum Mechanics, Metaphysics, and Bohm's Implicate Order." Mind and Matter 17 (2): 155-85.

Young, Iris Marion. 1990. Justice and the Politics of Difference. Princeton: Princeton University Press.

Zanotti, Laura. 2018. Ontological Entanglements, Agency and Ethics in International Relations. London: Routledge.

Cite this article: Wendt, A. 2022. "Why IR scholars should care about quantum theory, part II: critics in the PITs.” International Theory 14 (1), 193-209, doi:10.1017/S1752971921000105 